\title{
DKA management and outcomes
}

\author{
Francesco Chiarelli, M Loredana Marcovecchio \\ From 7th APPES Biennial Scientific Meeting \\ Nusa Dua, Bali. 14-17 November 2012
}

Diabetic ketocidosis (DKA) is an acute life threatening complication of type 1 diabetes mellitus (T1D). DKA is characterized by the the triad of hyperglycemia, metabolic acidosis and increased total body ketone concentration. These metabolic derangements result from the combination of absolute or relative insulin deficiency and increased levels of counter-regulatory hormones.

DKA is associated with both short-term risks and longterm consequences. Recent data have shown that DKA is responsible for up to $73 \%$ of causes of deaths during the first decade of diabetes. Mortality is predominantly related to the occurrence of cerebral edema, which occurs in $0.3-1 \%$ of patients, whereas only a minority of deaths in DKA is due to other causes.

DKA represents the initial manifestation of T1D in 13$80 \%$ of cases and it can also occur in $25 \%$ of cases of type 2 diabetes at onset. In addition, DKA is a common complication in patients with known diabetes, where it may be the consequence of illness, poor compliance, or malfunction of diabetes care equipment.

Early identification and treatment of DKA are two key points to minimizing the risks of this complication. Children with DKA should be treated in experienced centers and adherence to guidelines for the management of this condition is of paramount importance.

Treatment of DKA requires strict monitoring of the patient, correction of hyperglycemia, acidosis and ketosis and replacement of fluid and electrolytes losses.

Another important point is the identification and treatment of precipitating events.

Early recognition of signs indicative of cerebral edema is essential to prevent the morbidity and mortality associated with this complication. Cerebral edema occurs in $0.3-1 \%$ of patients in DKA and represents the most common cause of mortality in children with DKA, accounting for $60-90 \%$ of all DKA deaths. In addition, $10-25 \%$ of survivors have significant residual morbidity. The etiology of cerebral edema is poorly understood, but it is likely related to vasogenic, osmotic, and ischemic mechanisms.

Prevention of DKA at diagnosis is of paramount importance and should be based on intensive community interventions and education of health care providers to raise awareness. In addition, preventive strategies should be applied to avoid episodes of DKA in patients with an already known diagnosis of diabetes. This requires patient education and access to specific diabetes programs and services.

\section{Published: 3 October 2013}

\section{References}

1. Donaghue KC, Chiarelli F, Trotta D, Allgrove J, Dahl-Jorgensen K: Microvascular and macrovascular complications associated with diabetes in children and adolescents. Pediatr Diabetes 2009, 10(Suppl 12):195-203.

2. Dunger DB, Sperling MA, Acerini CL, Bohn DJ, Daneman D, Danne TP, Glaser NS, Hanas R, Hintz RL, Levitsky LL, Savage MO, Tasker RC,

Wolfsdorf Jl, European Society for Paediatric Endocrinology, Lawson Wilkins Pediatric Endocrine Society: European Society for Paediatric Endocrinology/Lawson Wilkins Pediatric Endocrine Society consensus statement on diabetic ketoacidosis in children and adolescents. Pediatrics 2004, 113(2):e133-40.

doi:10.1186/1687-9856-2013-S1-016

Cite this article as: Chiarelli and Marcovecchio: DKA management and outcomes. International Journal of Pediatric Endocrinology 2013 2013(Suppl 1):016.

Submit your next manuscript to BioMed Central and take full advantage of:

- Convenient online submission

- Thorough peer review

- No space constraints or color figure charges

- Immediate publication on acceptance

- Inclusion in PubMed, CAS, Scopus and Google Scholar

- Research which is freely available for redistribution

Department of Paediatrics, University of Chieti, Chieti, Italy 